\title{
Article
}

\section{Development of a novel, multifunctional, membrane-interactive pyridinium salt with potent anticancer activity}

Snape, Timothy James, Fahs, Sara, Rowther, Farjana, Dennison, Sarah Rachel, Patil-Sen, Yogita and Warr, Tracy

Available at http://clok.uclan.ac.uk/10611/

Snape, Timothy James ORCID: 0000-0003-2766-4491, Fahs, Sara, Rowther, Farjana, Dennison, Sarah Rachel ORCID: 0000-0003-4863-9607, Patil-Sen, Yogita and Warr, Tracy (2014) Development of a novel, multifunctional, membrane-interactive pyridinium salt with potent anticancer activity.

Bioorganic \& Medicinal Chemistry Letters, 24 (15). pp. 3430-3433. ISSN 0960$894 X$

It is advisable to refer to the publisher's version if you intend to cite from the work. http://dx.doi.org/10.1016/j.bmcl.2014.05.087

For more information about UCLan's research in this area go to

http://www.uclan.ac.uk/researchgroups/ and search for <name of research Group>.

For information about Research generally at UCLan please go to http://www.uclan.ac.uk/research/

All outputs in CLoK are protected by Intellectual Property Rights law, including Copyright law. Copyright, IPR and Moral Rights for the works on this site are retained by the individual authors and/or other copyright owners. Terms and conditions for use of this material are defined in the policies page. 


\section{Accepted Manuscript}

Development of a novel, multifunctional, membrane-interactive pyridinium salt with potent anticancer activity

Sara Fahs, Farjana B. Rowther, Sarah R. Dennison, Yogita Patil-Sen, Tracy Warr, Timothy J. Snape

PII: S0960-894X(14)00596-4

DOI: http://dx.doi.org/10.1016/j.bmcl.2014.05.087

Reference: BMCL 21701

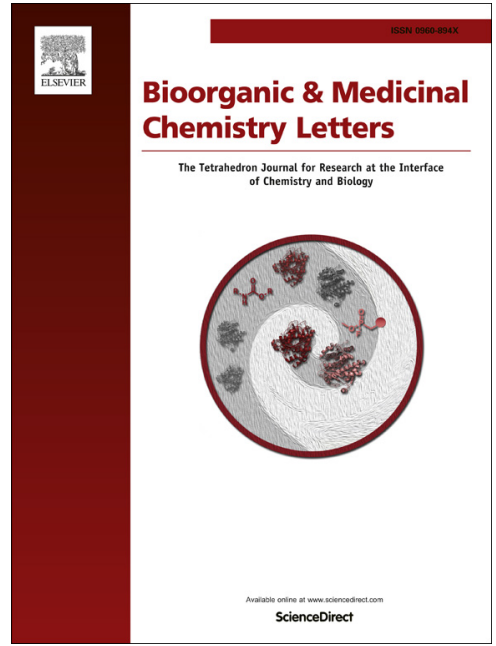

To appear in:

Bioorganic \& Medicinal Chemistry Letters

Received Date:

18 March 2014

Revised Date:

20 May 2014

Accepted Date:

22 May 2014

Please cite this article as: Fahs, S., Rowther, F.B., Dennison, S.R., Patil-Sen, Y., Warr, T., Snape, T.J., Development of a novel, multifunctional, membrane-interactive pyridinium salt with potent anticancer activity, Bioorganic \& Medicinal Chemistry Letters (2014), doi: http://dx.doi.org/10.1016/j.bmcl.2014.05.087

This is a PDF file of an unedited manuscript that has been accepted for publication. As a service to our customers we are providing this early version of the manuscript. The manuscript will undergo copyediting, typesetting, and review of the resulting proof before it is published in its final form. Please note that during the production process errors may be discovered which could affect the content, and all legal disclaimers that apply to the journal pertain. 


\section{Graphical Abstract}

To create your abstract, type over the instructions in the template box below.

Fonts or abstract dimensions should not be changed or altered.

Development of a novel, multifunctional, membrane-interactive pyridinium salt with potent anticancer activity

Leave this area blank for abstract info.

Sara Fahs, Farjana B. Rowther, Sarah R. Dennison, Yogita Patil-Sen, Tracy Warr, Timothy J. Snape*

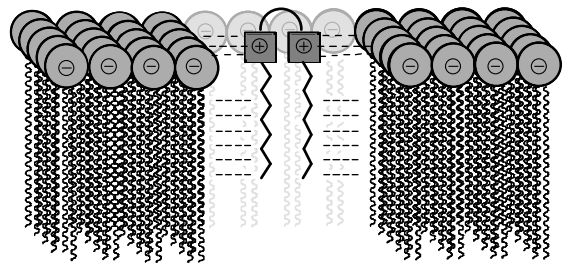

3 possesses potent micro-molar anticancer

activity. A membrane interactive process,

Coulombic forces, to help lyse the cell

membrane, is proposed.

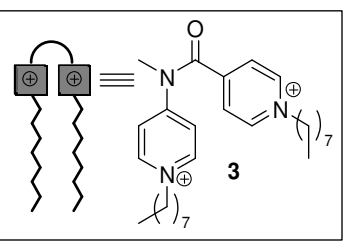




\title{
Bioorganic \& Medicinal Chemistry Letters \\ journal homepage: www.elsevier.com
}

\section{Development of a novel, multifunctional, membrane-interactive pyridinium salt with potent anticancer activity}

\author{
Sara Fahs, ${ }^{\mathrm{a}}$ Farjana B. Rowther, ${ }^{\mathrm{b}}$ Sarah R. Dennison, ${ }^{\mathrm{a}}$ Yogita Patil-Sen, ${ }^{\mathrm{a}}$ Tracy Warr, ${ }^{\mathrm{b}}$ Timothy J. Snape ${ }^{\mathrm{a}, *}$ \\ ${ }^{a}$ School of Pharmacy and Biomedical Sciences, University of Central Lancashire, Maudland Building, Preston, Lancashire, PRI 2HE, UK \\ ${ }^{b}$ Brain Tumour Research Centre, University of Wolverhampton, Wulfruna Street, Wolverhampton, WV1 ILY, UK
}

ARTICLE INFO

Article history:

Received

Revised

Accepted

Available online

Keywords:

Pyridinium salts

Anticancer

Glioma

Amide

Biocidal
ABSTRACT

The synthesis and biological evaluation of a novel pyridinium salt is reported. Initial membrane interaction with isolated phospholipid monolayers was obtained with the pyridinium salt, and two neutral analogues for comparison, and the anticancer effects of the best compound established using a cytotoxicity screening assay against glioma cells using both an established cell line and three short-term cell cultures - one of which has been largely resistant to all chemotherapeutic drugs tested to date. The results indicate that the pyridinium salt exhibits potent anticancer activity $\left(\mathrm{EC}_{50} \mathrm{~s}=9.8-312.5 \mu \mathrm{M}\right)$ on all cell types, including the resistant one, for a continuous treatment of 72 hours. Microscopic examination of the treated cells using a trypan blue exclusion assay showed membrane lysis had occurred. Therefore, this letter highlights the potential for a new class of pyridinium salt to be developed as a much needed alternative treatment for glioma chemotherapy.

2009 Elsevier Ltd. All rights reserved.
The pyridinium salts, 12-methacryloyloxydodecylpyridinium bromide (MDPB) and cetylpyridinium chloride (CPC, Fig. 1), have been identified as potent cytotoxic agents and have been extensively used in the dental profession for the treatment of oral infections. ${ }^{1}$ The cytotoxic mechanism of such quaternary ammonium compounds is believed to be due to the cationic pyridinium salts binding to negatively charged cell wall components. Consequently, this disturbs the membranes' electrical balance, and subsequently induces leakage of cytoplasmic material leading to cell death, ${ }^{2-4}$ a process which is presumably aided by the alkyl chains of MDPB and CPC penetrating and disrupting the hydrophobic lipid bilayer of the cell membrane simultaneously. Moreover, the associated drugs, perifosine and miltefosine (Fig. 1), which are structurally related to the phospholipid components of the cell membrane, are thought to exert their antineoplastic actions by disruption of cellmembrane function and thus they display significant antiproliferative activity in vitro and in vivo in several human tumour model systems and leishmaniasis. 5,6

In a mechanistically similar manner to such compounds, it has recently been demonstrated that certain aromatic molecules with a defined shape, and which are suitably adorned with long alkyl chains, behave similarly in being able to disturb lipid membranes (1, Fig. 1), ${ }^{7,8}$ but that, due to their distinctive three-dimensional shape, which places the two benzene rings adjacent to each other, are able to donate the two alkyl chains at the same time, thus potentially exert twice the membrane-disrupting capability to that of MDPB, CPC, perifosine and miltefosine at the same concentrations. Unfortunately, with such compounds (i.e. 1), the high hydrophobicity and thus poor water solubility somewhat limits their use as biocidal agents.

\section{$\mathrm{Xx}$}

Figure 1. The structures of MDPB, CPC, perifosine, miltefosine and the experimental compounds $\mathbf{1 - 3}$.

It was anticipated that the preparation of $\mathbf{3}$ would generate an amphiphilic compound that is structurally related to the known compounds shown in Fig. 1, but one that contains two charges and two alkyl chains, effectively doubling the interactions between the compound and the membrane. Additionally, the charges may also aid in the aqueous solubility of these compounds, a feature which has been problematic with similar compounds such as 1. Fig. 2 depicts a schematic representation of the proposed interactions expected between $\mathbf{3}$ and negatively charged membranes - thus ultimately causing membrane destabilization, lysis and a potential treatment for disease.

\section{$\mathrm{Xx}$}

Figure 2. A schematic depicting the proposed interaction of positively charged $\mathbf{3}$ with a negatively charged lipid monolayer.

The synthesis of compound $\mathbf{1}$ has been previously reported by us $^{7}$ and the synthesis of compounds $\mathbf{2}$ and $\mathbf{3}$ are outlined in Scheme 1.

$$
\mathrm{Xx}
$$

Scheme 1. The synthesis of compounds 2 and $\mathbf{3}$. 
Briefly, a successful union between $N$-methyl-4-pyridinamine (4) and isonicotinoyl chloride (5) was achieved in high yield (90\% after purification) to generate the desired $\mathrm{N}$-methylated amide product, 2. Subsequent bis-alkylation of $\mathbf{2}$ was then achieved in high yield (88\% after purification) with an excess of n-octyliodide to provide 3 .

\section{$\mathrm{Xx}$}

Figure 3. Percentage membrane lysis of calcein-entrapped vesicles made up of DMPG (A), DMPE (B), DMPS (C) and DMPC (D).

Grey circles $=\mathbf{1}$, black crosses $=\mathbf{2}$ and grey crosses $=\mathbf{3}$, where $n=5$ with error bars showing standard deviation. $\mathrm{DMPG}=$

dimyristoylphosphatidylglycerol, DMPE $=$

dimyristoylphosphatidylethanolamine, DMPS =

dimyristoylphosphatidylserine and DMPC $=$

dimyristoylphosphatidylcholine.

Having the compounds to hand, their ability to lyse membranes of calcein-entrapped vesicles was determined. As can been seen from Fig. 3, all membranes [DMPG (A), DMPE (B), DMPS (C) and DMPC (D)] are lysed to similar maximal levels ( $60-80 \%)$; however, each of the three compounds 1-3 lyse the four membranes to differing extents, but always with the same order of activity for each compound, demonstrating the dependence of the release on the vesicle membrane composition, as has been shown in related work with CPC. ${ }^{9}$ For example, all membranes are lysed to the greatest extent with $\mathbf{3}$, whilst the lowest levels of membrane lysis are brought about by $\mathbf{2}$, making the activity of $\mathbf{1}$ somewhere in between. Gratifyingly, this correlates exactly with what was expected with regard to the working hypothesis depicted in Fig. 2, in that the neutral compound 2, which lacks any alkyl groups, interacts more weakly with all the membranes giving rise to a maximum lysis of $\sim 40-50 \%$. Presumably, at the $\mathrm{pH}$ of the lysis experiments, enough protonation of the pyridine nitrogen's in $\mathbf{2}$ can occur, meaning that this (now pyridinium) compound can interact with the polar lipid head groups and H-bond to unprotonated molecules of 2 thus associate at the lipid surface, thus causing some disruption of the lipid packing and its electrical balance, but since it lacks the alkyl groups, $\mathbf{2}$ cannot penetrate deeply into the membrane and cause maximal membrane damage. Conversely, the neutral compound 1, which does contain the lipid-penetrating alkyl groups, but is uncharged, is able to interact better with the hydrophobic lipid chains, but it cannot interact strongly with the polar headgroups, thus resulting in a maximum membrane lysis of $\sim 60-70 \%$. However, the charged compound (3) presumably experiences a greater attractive force to the negatively charged components of the membranes, as well as possessing the lipidpenetrating alkyl groups thus resulting in a percentage lysis range of $70-80 \%$. Moreover, although the concentration range was extended into milli-molar values to obtain the plateau at which maximal lysis occurs, it should be noted that that gradient of the curves at micro-molar concentrations is steep enough to give rise to similar values of membrane lysis to the maximal values obtained (i.e. the plateau of membrane lysis occurs quickly and at micro-molar concentrations in most cases); as such, for a direct comparison at a single concentration, Table 1 outlines the percent lysis obtained at $187.5 \mu \mathrm{M}$. As can be seen, compound $\mathbf{3}$ is able to lyse all four lipids studied to the highest levels, whereas compound $\mathbf{2}$ is equipotent to $\mathbf{1}$ against DMPE, DMPS and DMPC, but is able to lyse almost twice as much of the liposomes composed of DMPG than 1, suggesting that charge (under the experimental conditions) is more dominant than the alkyl chains; a facet supported by the structure of $\mathbf{3}$, which has both. Moreover, whilst the liposomes composed of lipids representative of mammalian cancer cells (DMPC), ${ }^{10}$ were only lysed to $\sim 39 \%$ with 3 , those liposomes composed of the main constituent lipid from E. coli cells (DMPE) were lysed by $\sim 80 \%$ with $3,{ }^{10}$ suggesting that future studies of this compound could be important in the development of new antimicrobial agents, especially since it has been shown that alkyl chain length can be tuned to optimise membrane perturbation, ${ }^{11}$ and control the mode of action as well. ${ }^{12}$

Table 1. Calcein release assay: percentage calcein release for compounds 1-3 against the four lipid vesicles. The values shown are the average and standard deviations of five experiments at a single concentration of $187.5 \mu \mathrm{M}$.

\begin{tabular}{lllll}
\hline Compound & DMPG & DMPE & DMPS & DMPC \\
\hline $\mathbf{1}$ & $16.6 \pm 5.7$ & $34.7 \pm 1.3$ & $27.2 \pm 2.6$ & $27.3 \pm 0.1$ \\
$\mathbf{2}$ & $30.0 \pm 5.4$ & $34.9 \pm 0.9$ & $23.3 \pm 2.1$ & $34.1 \pm 0.2$ \\
$\mathbf{3}$ & $44.2 \pm 6.8$ & $77.7 \pm 2.9$ & $64.6 \pm 2.1$ & $38.8 \pm 0.2$ \\
\hline
\end{tabular}

Based on these encouraging results, and in continuation of our efforts to try and develop new treatments for malignant brain tumours, it was of interest to us to determine what effects the most potent compound (3) has against glioma cells available to us through the Brain Tumour North West alliance. ${ }^{13}$

Three short-term cultures (IN1528, IN1760 and IN1472) and one established cell line (U251-MG) were used in this study to determine the potential anti-proliferative effects of the best membrane-interactive compound (3) on whole cells using a sulphorhodamine-B assay. The neutral compound (1) was shown to precipitate from the media and was not used further presumably, the different media used in the calcein and cytotoxicity assays, largely additional amino acids, vitamins, inorganic salts and other components, causes the differing solubilities of $\mathbf{1}$ in the two assays. A range of concentrations of the test compound $(1-5000 \mu \mathrm{M}$, in triplicate) were screened and the $\mathrm{EC}_{50} \mathrm{~s}$ determined (Table 2). Compound $\mathbf{3}$ inhibited proliferation in all GBM cells studied at low (micro-molar) levels, particularly in the short-term cultures which are more representative of primary tumours in vivo. Importantly, compound $\mathbf{3}$ was also shown to be extremely potent against the highly resistant cell culture IN1760, a culture which has proved to be highly resistant to a number of commercially available anticancer drugs (CCNU, vincristine and doxorubicin), ${ }^{14}$ indicating that this class of molecule holds potential for further development as a glioma therapy of the future.

Table 2. $\mathrm{EC}_{50}$ values of compound $\mathbf{3}$ against various glioma cells.

\begin{tabular}{ll} 
GBM cultures & $\mathrm{EC}_{50}(\mu \mathrm{M})^{\mathrm{a}}$ \\
\hline IN1528 & 9.8 \\
IN1760 & 19.5 \\
IN1472 & 78.0 \\
U251-MG & 312.5
\end{tabular}

${ }^{\mathrm{a}} \mathrm{EC}_{50}$ is the $50 \%$ effective concentration of compound $\mathbf{3}$ which induces a response halfway between the baseline and maximum values after $72 \mathrm{~h}$.

Having determined the anticancer activity of pyridinium salt 3 on all glioma cell cultures examined, the exact mechanism of cell death was briefly probed. A dye exclusion assay, using the dye trypan blue, was performed to detect any membrane lysis that might be occurring early on post-treatment. In separate experiments, all cell cultures were studied microscopically, whereby it was observed that at both 200 and $500 \mu \mathrm{M}$ of compound $\mathbf{3}$, the cells stained positive for trypan blue, as 
indicated by the ready uptake of the dye, suggesting that $\mathbf{3}$ is able to compromise the cell membrane and enable the dye to pass through, but at these concentrations there is not enough of it accumulating at the cell surface to completely obliterate the cells (see Supp. Info.). Conversely, for comparison, at $1000 \mu \mathrm{M}$ the cells appeared completely obliterated and there was no cell structure remaining to contain the trypan blue dye.

Together the above data suggests that at certain micro-molar concentrations (Fig. 3 and Table 1) compound $\mathbf{3}$ is present at the membrane in sufficient concentrations to be able to bind to it through an initial electrostatic interaction with the lipid headgroups, and following insertion in to the membrane, cause it to become compromised. The elucidation and concentration effects of the exact molecular pathways employed by this pyridinium salt in glioma cells, as well as aqueous solubility optimisation studies are the focus of an on-going study.

In conclusion, the synthesis and biological evaluation of a novel pyridinium salt $(\mathbf{3})$ has been reported which combines the favourable features of $\mathbf{1}$ (possessing two lipid-penetrating alkyl chains) and $\mathbf{2}$ (possessing two positive charges when subjected to the experimental conditions). Interactions with both isolated phospholipid monolayers and glioma cells were obtained with the pyridinium salt and two neutral analogues. The results indicate that the pyridinium salt (3) exhibits potent anticancer activity $\left(\mathrm{EC}_{50} \mathrm{~s}=9.8-312.5 \mu \mathrm{M}\right)$ on all cell types, including a resistant one, and a trypan blue dye exclusion assay suggests that the exact mechanism of cell death is due to membrane lysis. Due to the known differing lipid composition of cancer cells versus healthy mammalian cells, compound $\mathbf{3}$ and its prospective analogues, may present a promising approach to selectively target cancer cells and thus have the potential to be developed further into alternative treatments for glioma chemotherapy in the future.

\section{Acknowledgments}

This work was part-funded by The Colin Oliphant Trust and Brain Tumour North West and the authors would like to thank them, along with the EPSRC National Mass Spectrometry Facility (NMSF).

\section{References and notes}

1. Sreenivasan, P.; Gaffar, A. J. Clin. Periodontol. 2002, 29, 965.

2. Imazato, S.; Ebi, N.; Tarumi, H.; Russell, R. R. B.; Kaneko, T.; Ebisu, S. Biomaterials 1999, 20, 899.

3. Imazato, S.; Kuramoto, A.; Takahashi, Y.; Ebisu, S.; Peters, M. C. Dent. Mater. 2006, $22,527$.

4. Scheie, A. A. J. Dent. Res. 1989, 68, 1609.

5. Gills, J. J.; Dennis, P. A. Curr. Oncol. Rep. 2009, 11, 102.

6. Dorlo, T. P. C.; Balasegaram, M.; Beijnen, J. H.; de Vries, P. J. J. Antimicrob. Chemother. 2012, 67, 2576.

7. Dennison, S. R.; Akbar, Z.; Phoenix, D. A.; Snape, T. J. Soft Matter 2012, 8, 3258.

8. Dennison, S. R.; Snape, T. J.; Phoenix, D. A. Eur. Biophys. J. 2012, 41, 687 .

9. Marcotte, L.; Barbeau, J.; Edwards, K.; Karlsson, G.; Lafleur, M. Colloids Surf., A 2005, 266, 51.

10. Lohner, K.; Prenner, E. J. Biochim. Biophys. Acta 1999, 1462, 141.

11. Wang, Y.; Jones, E. M.; Tang, Y.; Ji, E.; Lopez, G. P.; Chi, E. Y.; Schanze, K. S.; Whitten, D. G. Langmuir 2011, 27, 10770.

12. Togashi, N.; Shiraishi, A.; Nishizaka, M.; Matsuoka, K.; Endo, K.; Hamashima, H.; Inoue, Y. Molecules 2007, 12, 139.

13. http://www.btnw.org.uk/

14. Personal communication with Dr Tracy Warr, University of Wolverhampton, UK.

\section{Supplementary Material}

Supporting information for this article is available. 
<smiles></smiles>

MDPB<smiles>CC(C)(C)[n+]1ccccc1</smiles>

CPC

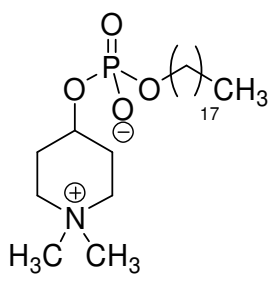

Perifosine<smiles>C[N+](C)(C)CCOP(=O)([O-])OC1CC1</smiles>

Miltefosine<smiles>CCc1ccc(N(C)C(=O)c2ccc(C(C)C)cc2)cc1</smiles><smiles>CN(C(=O)c1ccncc1)c1ccncc1</smiles><smiles>CC(C)[n+]1ccc(C(=O)N(C)c2cc[n+](C(C)C)cc2)cc1</smiles>

Figure 1
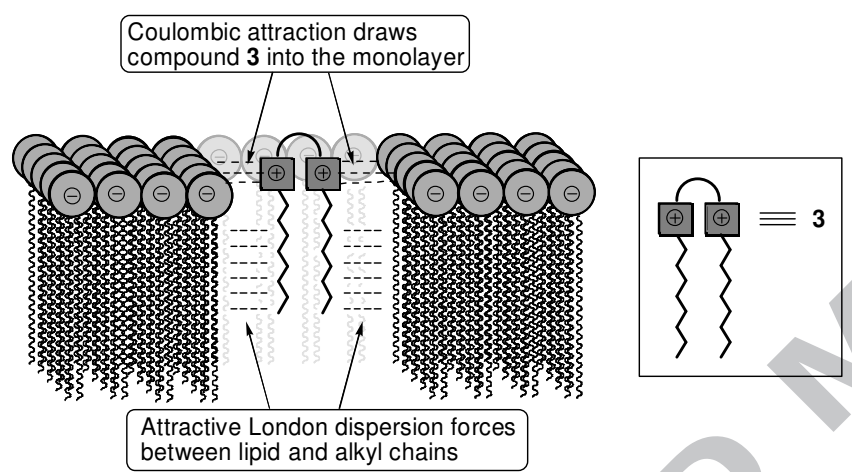

Figure 2

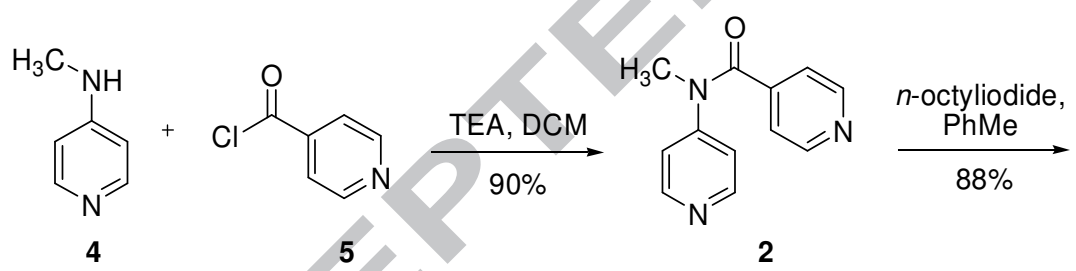

\section{Scheme 1}<smiles>CC[n+]1ccc(C(=O)N(C)c2cc[n+](C(C)C)cc2)cc1</smiles> 


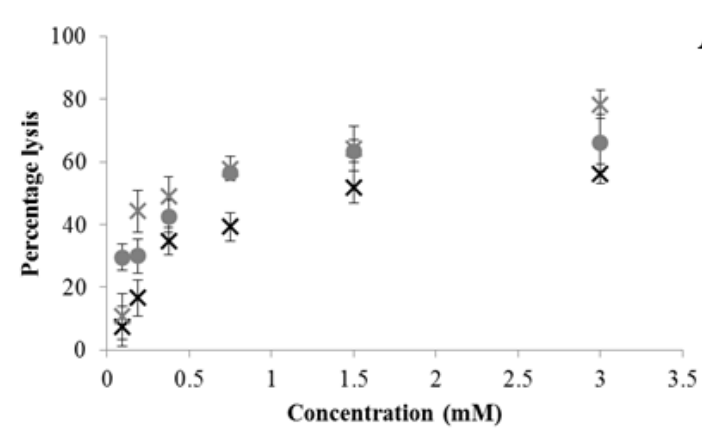

A 1007 B
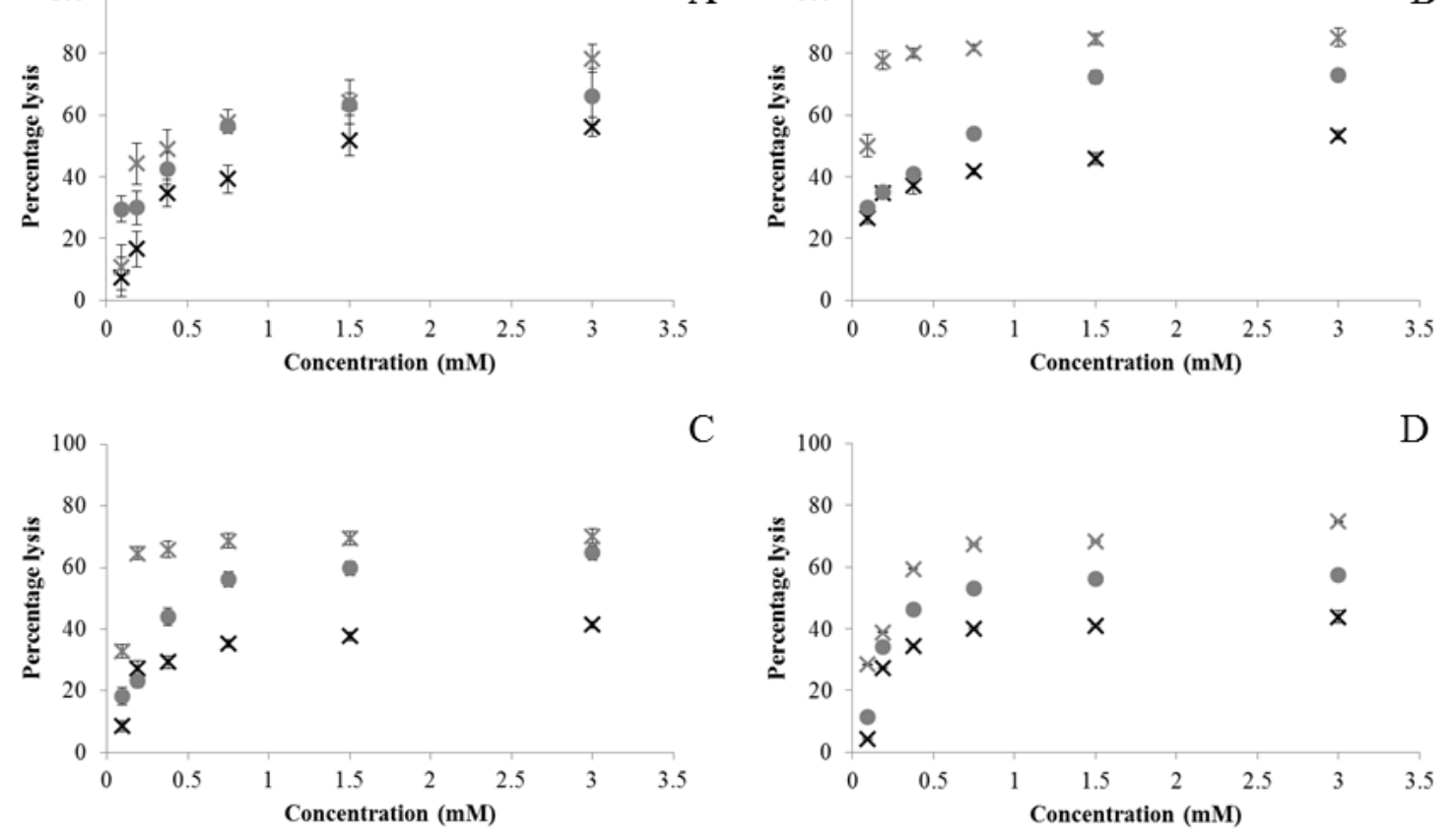

C

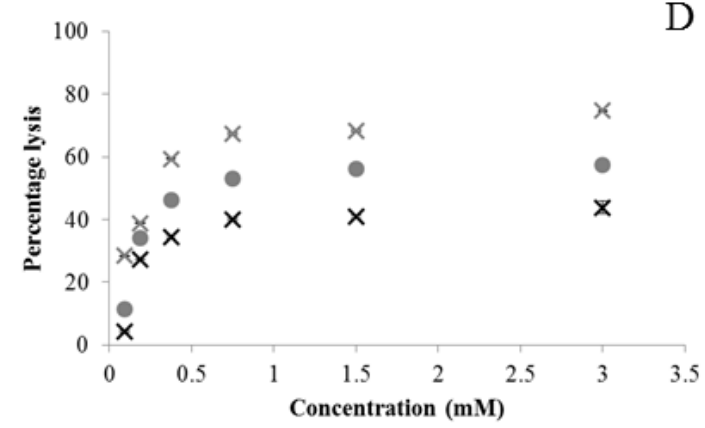

Figure 3 